\title{
Um novo gênero e espécie de Blattellidae neotropical (Blattaria)
}

\author{
Sonia Maria Lopes \& Edivar Heeren de Oliveira
}

Departamento de Entomologia, Museu Nacional, Universidade Federal do Rio de Janeiro. Quinta da Boa Vista, São Cristóvão, 20940-040 Rio de Janeiro, Brasil. (sonialf@acd.ufrj.br).

ABSTRACT. A new genus and species of neotropical Blattellidae (Blattaria). In this paper, a new genus and species from the state of Minas Gerais, Brazil, is described. The male genitalia is illustrated. The new genus is similar to Cariblatta and Neoblattella.

KEYWORDS. Cariblattella, new genus, new species, Minas Gerais, taxonomy.

RESUMO. Neste trabalho descreve-se um novo gênero e espécie do Estado de Minas Gerais, Brasil. A genitália do macho é ilustrada. O novo gênero é similar a Cariblatta e Neoblattella.

PALAVRAS-CHAVE. Cariblattella, gênero novo, espécie nova, Minas Gerais, taxonomia.

Cariblatta foi descrito por HeBARd (1916) e atualmente conta com 67 espécies conhecidas, que se encontram distribuídas nas três Américas, com maior incidência na América Central e América do Sul.

O gênero Neoblattella foi descrito por SHELFORD (1911) com base em Blatta adspersicollis Stål, 1858.

REHN (1915), a partir de uma fêmea, descreveu uma espécie nova da Argentina, N. puerilis Rehn, 1915; em 1932, o mesmo autor descreveu N. sucina Rehn, 1932, com base em material do Estado do Pará (ReHN, 1932).

BRUIJNING (1959), estudando o gênero Neoblattella, considerou a ele pertencentes somente seis espécies, englobando-as no grupo que denominou como adspersicollis [N. adspersicollis (Stål, 1861); N. binodosa Hebard, 1926; N. poecilops Hebard, 1926; N. longior Hebard, 1926; N. unifascia Hebard, 1926 e N. guianae Hebard, 1929].

Neste trabalho, descrevem-se um gênero novo e uma espécie nova de Blattellidae, Pseudophyllodromiinae, do Estado de Minas Gerais e ilustra-se a genitália masculina da espécie. Foram analisados caracteres morfológicos relacionados à coloração geral, espinhos das pernas, tipo de unhas, placas genitais e genitália do macho, o que permitiu a sua comparação com espécies de Cariblatta e Neoblattella.

\section{MATERIAL E MÉTODOS}

O material foi coletado no município de Pedra Azul, Estado de Minas Gerais (16 00 '18'S, $41^{\circ} 17^{\prime} 49^{\prime}$ 'W), região de vegetação de Cerrado, com variações desde cerradão até campo sujo, com ocorrência de Mata Atlântica. O município possui área de $1.624 \mathrm{~km}^{2}$ (IBGE, 2007) e localizase a uma altitude de $617 \mathrm{~m}$ (CITYBRAZIL, 2007).

A observação das placas genitais foi feita através da retirada da parte final do abdome do exemplar macho, designado como holótipo, utilizando-se técnicas tradicionais para dissecção (LOPES \& OliveirA, 2000). A designação das peças genitais foi baseada nos conceitos propostos por McKITTRICK (1964).
O material encontra-se depositado na coleção do Departamento de Entomologia do Museu Nacional, Universidade Federal do Rio de Janeiro (MNRJ).

\section{Cariblattella gen. nov.}

Espécie-tipo. Cariblattella petrazulana sp. nov. Etimologia. O nome do gênero originou-se da combinação de Cariblatta e Neoblattella.

Descrição. Pronoto curto e alargado, com manchas na região central. Abdome com manchas nos tergitos e esternitos. Tégminas longas, ultrapassando em comprimento o ápice dos cercos, com o campo escapular oblíquo. Asas com campo anterior apresentando os ápices dos ramos da nervura radial dilatados, triângulo apical não desenvolvido e campo anal dobrado em leque. Fêmures das pernas anteriores, na face ântero-ventral, com uma série decrescente de espinhos, distribuídos da base em direção ao ápice, finalizando em dois apicais distintos; na face póstero-ventral com dois espinhos fortes no terço apical e um apical robusto; unhas simétricas e serrilhadas internamente.

O gênero descrito como novo foi assim determinado e denominado por apresentar: as placas subgenital, supraanal, falômero direito e esquerdo característicos de Cariblatta, porém dele distanciando-se em relação à configuração do exemplar e ao esclerito mediano, que por ser bifurcado se aproxima de Neoblattella.

\section{Cariblattella petrazulana sp. nov. (Figs. 1-8)} de coleta.

Etimologia. O nome da espécie deve-se à localidade

Descrição. Holótipo đ. Coloração geral castanhoclara, amarelada e brilhante (Fig. 1). Olhos negros (Fig. 2), segmento apical do palpo maxilar com tomentosidade dourada. Fronte, abdome e disco central do pronoto leitosos, este com pequenas manchas castanhas mais escuras (Fig. 3). Ápice dos ramos da nervura radial das 
asas mais escuros. Abdome com pequenas manchas circulares castanho-escuras nos tergitos e esternitos.

Cabeça triangular e alargada, com vértice exposto, espaço interocular amplo, medindo cerca da metade da área que separa as bases das inserções antenais; fronte saliente e projetada (Fig. 2). Antenas longas, filiformes e tomentosas, atingindo o ápice do abdome; palpos maxilares tomentosos, terceiro artículo igual em comprimento à área que separa as bases das inserções antenais, quarto artículo menor que o terceiro e quinto artículo curto e muito dilatado.

Pronoto transverso, curto e alargado, ápice reto, base levemente angular e abas laterais amplas e de contorno arredondado (Fig. 3), disco central pequeno. Tégminas longas, ultrapassando em comprimento o ápice dos cercos, campo marginal curto e bem marcado; campo escapular oblíquo; campo discoidal amplo e longitudinal e campo anal bem desenvolvido. Asa com campo anterior apresentando os ápices dos ramos da nervura radial dilatados, triângulo apical não desenvolvido e campo anal dobrado em leque. Pernas desenvolvidas e alongadas; fêmur anterior, na face ântero-ventral, com uma série

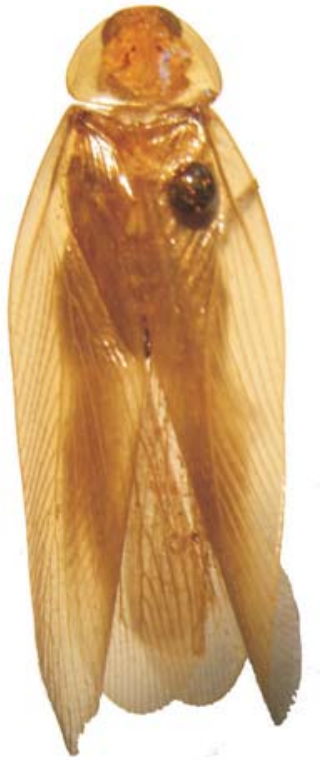

Fig. 1. Cariblattella petrazulana sp. nov., holótipo ơ: habitus, dorsal.
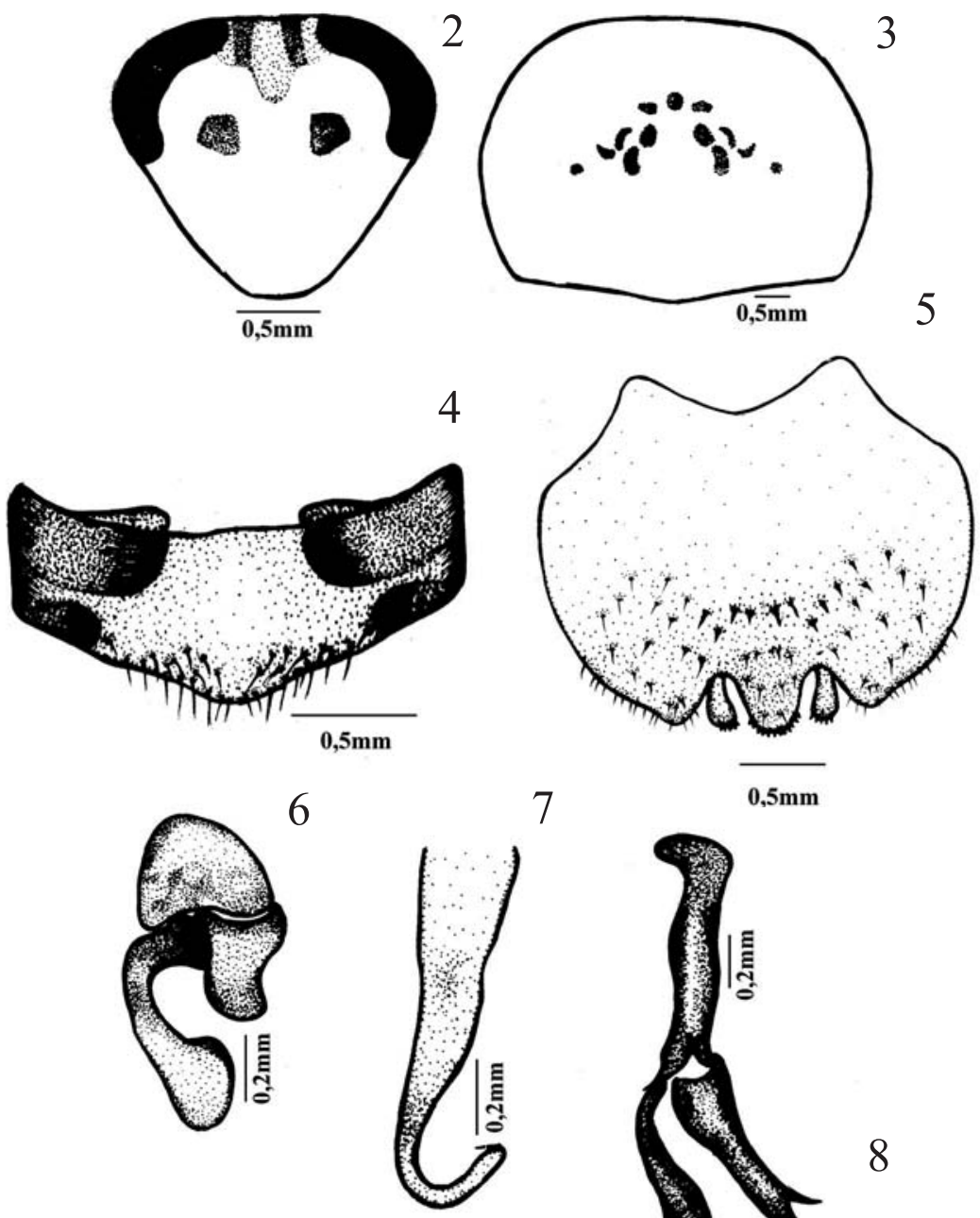

7

$0,5 \mathrm{~mm}$

Figs. 2-8. Cariblattella petrazulana sp. nov., holótipo ơ: 2, cabeça, ventral; 3, pronoto, dorsal; 4, placa supra-anal, dorsal; 5, placa subgenital, ventral; 6, falômero esquerdo, dorsal; 7, falômero direito, dorsal; 8, esclerito mediano, dorsal. 
decrescente de espinhos, da base em direção ao ápice, terminando em dois apicais, sendo um deles maior que o outro; face póstero-ventral com dois espinhos fortes no terço apical, mais um apical robusto; fêmures médio e posterior com espinhos grandes e esparsos, com um apical, disposição semelhante nas faces ântero e pósteroventrais. Tarsos desenvolvidos, pulvilos e arólios presentes em todos os artículos. Unhas simétricas e especializadas, com quatro dentes ventrais, crescentes em direção ao ápice da unha. Abdome com placa supraanal curta e com cerdas no bordo apical (Fig. 4). Placa subgenital simétrica, alargada e cerdosa, com projeção arredondada entre os estilos, cuja borda apical apresenta pequenos espinhos; estilos alargados, simétricos, com espinhos diminutos no bordo apical (Fig. 5). Falômero esquerdo em forma de $\mathrm{U}$ invertido, com uma das extremidades mais desenvolvida e arredondada (Fig. 6). Falômero direito em forma de gancho bem definido e afilado com um espinho pequeno no ápice (Fig. 7). Esclerito mediano curto, bifurcado e assimétrico, o ramo mais longo apresenta uma fileira de espinhos ciliformes na borda externa até o ápice, o ramo menor bifurcado e com pontas afiladas apicalmente (Fig. 8).

Medidas em mm. Holótipo ơ. Comprimento total, 15,0; comprimento do pronoto, 2,5; largura do pronoto, 3,5; comprimento da tégmina, 13,5; largura da tégmina, 3,5 .

Material-tipo. Holótipo $ð$, BRASIL, Minas Gerais: Pedra Azul, 800 m, XI.1972, Seabra \& Oliveira col.; parátipos: 5 đ", mesmos dados do holótipo.

A espécie apresenta similaridade com as de Cariblatta e Neoblattella pela forma e estrutura geral e pela presença de unhas tarsais especializadas. Porém delas distingue-se pela configuração: 1) da placa subgenital; 2) dos estilos, os quais são simétricos, com espinhos diminutos nos bordos apicais; 3 ) pela presença do esclerito mediano curto, com o ápice bifurcado e assimétrico; 4) pela faixa interocular; 5) pela disposição dos espinhos da perna.

Agradecimentos. Ao Conselho Nacional de Desenvolvimento Científico e Tecnológico (CNPq) e Fundação de Amparo à Pesquisa do Estado do Rio de Janeiro (FAPERJ), pelo apoio financeiro.

\section{REFERÊNCIAS BIBLIOGRÁFICAS}

Bruijning, C. F. A. 1959. The Blattidae of Suriname. Studies on the Fauna of Suriname and other Guyanas 2(4):1-103. CityBrazil. 2007. Disponível em: <http://www.citybrazil.com. br/mg/pedraazul/index.htm>. Acesso em: 11.07.2007.

Hebard, M. 1916. A new genus Cariblatta of the group blattellites. Transactions of the American Entomological Society 42:147-186.

IBGE. Instituto BrasiLeiro de Geografia e Estatística. 2007. Disponível em: <http://www.ibge.gov.br>. Acesso em: 11.07.2007.

Lopes, S. M. \& Oliveira, E. H. 2000. Espécie nova de Blaberus Serville, 1831 do Estado de São Paulo, Brasil (Blaberidae, Blaberinae). Boletim do Museu Nacional, Nova Série Zoologia, 415:1-4.

McKittrick, F. A. 1964. Evolutionary studies of cockroaches. Cornell University Agricultural Experiment Station Memoirs 389:1-197.

Rehn, J. A. G. 1915. A further contribution to the knowledge of the Orthoptera of Argentina. Proceedings of Academy of Natural Sciences 67:270-292.

1932. Wissenschaftliche Ergebnisse der Schwedische entomologischen Reisen des Herrn Dr A. Roman in Amazonas 1914-1915 und 1923-1924. Arkiv för Zoologi 24A(11):1-73.

SHELFORD, R. 1911. Preliminary diagnoses of some new genera of Blattidae. Entomologist's Monthly Magazine, second series, 47:154-156.

Recebido em outubro de 2006. Aceito em abril de 2007. ISSN 0073-4721

Artigo disponível em: www.scielo.br/isz 